\title{
Disiplin Kerja Dalam Perspektif Islam Dan Produktivitas Kerja Karyawan
}

\author{
Tuti Soleha
}

\begin{abstract}
ABSTRAK
Pengaruh Disiplin Kerja Dalam Perspektif Islam Terhadap Produktivitas Kerja Karyawan Pada PT. Kreasindo Cipta Karya Periode Februari - April 2016. Penelitian ini bertujuan untuk mengetahui ada tidaknya pengaruh positif langsung antara disiplin kerja dalam perspektif Islam terhadap produktivitas kerja karyawan pada PT. Kreasindo Cipta Karya Periode Februari-April 2016.

Penelitian ini menggunakan metode deskriptif kuantitatif, sampel dalam penelitian ini adalah sebanyak 30 responden, pengumpulan data menggunakan angket kuesioner dan dianalisis menggunakan regresi linear sederhana $\breve{Y}=a+b x$.

Hasil penelitian ini dilihat dari perhitungan determinasi $R^{2}$ sebesar $69 \%$ sedangkan thitung $(7,913)>$ tabel $(1,701)$ dan dapat dilihat nilai probabilitas pada kolom signifikan adalah 0,000 atau probabilitas di bawah 0,05 $(0,000<0,05)$ yang berarti membuktikan adanya pengaruh langsung positif dan signifikan antara disiplin kerja dalam perspektif Islam terhadap produktivitas kerja karyawan pada PT. Kreasindo Cipta Karya Periode Februari-April 2016.

Kata Kunci: Disiplin Kerja Dalam Perspektif Islam, Produktivitas Kerja
\end{abstract}

\section{PENDAHULUAN}

\section{A. Latar Belakang Masalah}

Bekerja dalam perspektif Islam adalah sarana dalam memperoleh rezeki dan kelayakan hidup, Rasulullah SAW megajukan bekerja, mendorongnya, dan berpesan agar pekerjaan dilakukan secara profesional, sebagaimana juga berpesan untuk berbuat adil dan tepat waktu dalam menggaji pekerja. Rasulullah SAW bersabda: "Sesungguhnya Allah ta'ala senang melihat hamba-Nya bersuassah payah (kelelahan) dalam mencari rezeki yang halal". (HR. Adailani).

Yang akan mempengaruhi produktivitas kerja adalah disiplin kerja. Disiplin adalah kemampuan mengendalikan diri dengan tetap taat walaupun dalam situasi yang sangat menekan. Orang yang memiliki disiplin sangat berhati-hati dalam mengelola pekerjaannya serta penuh tanggung jawab memenuhi kewajibannya. Disiplin kerja dalam Islam dijelaskan dalam hadist yaitu: "Seorang muslim wajib mendengar dan taat, baik dalam hal yang disukainya maupun hal yang dibencinya, kecuali bila ia diperintah untuk mengerjakan maksiat. Apabila ia diperintah 
mengerjakan maksiat, maka tidak wajib untuk mendengar dan taat", (H.R. Bukhari Muslim). Seorang muslim adalah seorang pekerja keras, mempunyai disiplin kerja yang tinggi, produktif, dan inovatif. Seorang muslim harus menyadari sepenuhnya bahwa pekerja yang dilakukan didorong oleh kesadaran untuk melaksanakan kewajiban yang diperintah Allah SWT. Selama dibuat sebagai bentuk turunan dari akad kerja yang telah disepakati antara karyawan dan perusahaan, setiap karyawan wajib untuk terkait dengan tata tertib kerja. Dalam surat An Nisa ayat 59 Allah SWT berfirman: "Wahai orang orang yang beriman, taatlah kamu kepada Allah dan taatlah kepada rasul-Nya dan Kepada Ulil Amri dari (kalangan) kamu". Namun, bila ada hal-hal dalam tata tertib perusahaan yang ternyata bertentangan dengan syariat Islam, karyawan harus melakukan amar ma'ruf dan nahi munkar agar hal-hal yang dimaksud dapat diganti dan dihapus.

Berdasarkan hasil observasi peneliti pada perusahan PT. Kreasindo Cipta Karya pada dasarnya disiplin kerja masih sulit di wujudkan, ukuran yang dipakai dalam menilai apakah pegawai tersebut disiplin atau tidak, dapat terlihat dari ketepatan waktu kerja, ketaatan pada peraturan yang telah ditentukan oleh perusahaan, dan kurangnya komunikasi antara atasan dengan bawahan yang tidak harmonis. Kewajiban untuk meningkatkan disiplin kerja bukan hanya tugas karyawan saja, melainkan kewajiban para pemimpin perusahaan yang harus menyadari bahwa mereka memiliki tanggung jawab yang besar untuk membina karyawan.

Kejadian-kejadian seperti ini juga dikarenakan tidak tegasnya pemimpin dalam memberikan sanksi kepada karyawan yang tidak disiplin menyebabkan tingginya angka absensi karyawan yang berpengaruh terhadap tidak tercapainya target waktu produksi yang telah ditetapkan oleh perusahaan. Selain itu, kurang disiplinnya pencapaian target produksi dikarenakan kelambatan prosedur untuk mendapatkan persetujuan tindakan dari pimpinan, sehingga dalam proses produksi kekurangan pasokan atau bahan baku. Apabila hal seperti ini tidak di tangani dengan cepat, maka akan berpengaruh terhadap pendapatan perusahaan yang tidak stabil.

\section{Pengertian Disiplin Kerja}

Menurut Sutrisno (2014:87), disiplin merupakan alat penggerak karyawan. Agar tiap pekerjaan dapat berjalan dengan lancar, maka harus diusahaan agar ada disiplin kerja yang baik. Disiplin sebagi suatu kekuatan yang berkembang di dalam tubuh karyawan dan menyebabkan karyawan dapat menyesuaikan diri dengan sukarela pada keputusan, peraturan, dan nilai- nilai tinggi dari pekerjaan dan perilaku. Dalam arti 
sempit, biasanya dihubungkan dengan hukuman. Padahal sebenarnya menghukum seorang karyawa hanya merupakan sebagian dari persoalan disiplin. Hal demikian jarang terjadi dan hanya dilakukan bilamana usaha-usaha pendekatan secara konstruktif menglami kegagalan.

Menegakan disiplin kerja adalah memberlakukan peraturan dan tata tertib kerja dengan menanamkan etika serta norma kerja, mengemukakan bahwa seorang pekerja yang mempunya komitmen terhadap agamanya, tidak akan melupakan etika serta norma kerja yang diajarkan oleh agamanya. Dalam Al-Quran dijelaskan pada surat Al-Asr ayat 3 yaitu:

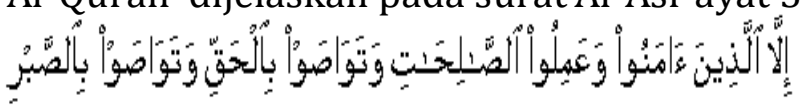

Artinya "Kecuali orang-orang yang beriman dan mengerjakan kebajikan serta saling menasehati untuk kebenaran dan saling menasehati untuk kesabaran".

Sehingga akan tercipta susana kerja yang tertib, aman, tenang, dan menyenangkan. Sehingga akan menunjang tercapainya produktivitas dan efisiensi kerja optimal.

\section{Pengertian Produktivitas Kerja}

Menurut Artyasa (2012:25), Islam adalah agama dengan pijakan tauhid yang jelas dan kokoh. Setiap muslim, apapun profesinya, selanjutnya menjadi perjuang tangguh. Jika ia seorang pebisnis, ia harus menjadi pebisnis yang menjadikan Allah sebagai pijakannya dan memiliki produktivitas yang tinggi. "Produktivitas kerja", kata inilah yang lazim disuarakan diberbagai instasi, lebih-lebih para pembisnis. Islam merupakan agama amaliah, agama tindakan (action), bukan agama konsepsi.

Islam adalah agama yang mengutamakan dan mengedepankan nilai-nilai produktivitas dan dinamika secara sempurna. Ayat yang menyatakan:

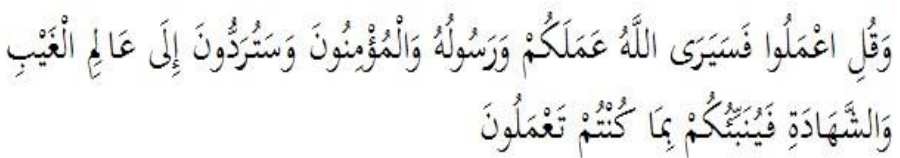

"Bekerjalah kamu maka Allah akan melihat pekerjaanmu, begitu juga rasulnya dan orang-orang mukmin, dan kamu akan dikembalikan kepada Allah yang mengetahui yang gaib dan yang nyata, lalu diberitahukan kepada kamu apa yang telah kamu kerjakan". (QS. At-Taubah: 105) merupakan salah satu bukti Al-Quran mengajarkan tentang produktivitas. 
Menurut Afandi (2016:74). Produktivitas adalah perbandingan secara ilmu hitung antara jumlah yang dihasilkan dan jumlah setiap sumber yang dipergunakan selama produksi berlangsung.

\section{Jenis Penelitian}

Dalam penelitian ini penulis melakukan penelitian dengan metode deskriptif kuantitatif. Data yang dilakukan dalam penelitian ini adalah data kuantitatif yang berupa data primer dan sekunder.

\section{Populasi}

Obyek dalam penelitian ini adalah populasi karyawan PT. Kreasindo Cipta Karya sebanyak 30 karyawan.

\section{Teknik Pengumpulan Data}

\section{Angket atau Kuesioner}

Kuesioner merupakan tekhnik pengumpulan data yang dilakukan dengan cara memberi seperangkat pertanyaan atau pertanyan tertulis kepada responden untuk dijawabnya.

\section{Metode Dokumentasi}

Metode dokumentasi yaitu mencari data mengenai hal - hal atau variabel yang berupa catatan, transkip, buku, surat kabar, majalah, agenda dan sebagainya.

\section{Data Lain}

Data lain ini bersumber dari referensi studi kepustakaan melalui jurnal, artikel dan bahan lain dari berbagai situs website yang mendukung.

\section{Teknik Analisa Data}

\section{Uji Validitas}

Validiatas adalah instrument tersebut dapat digunakan untuk mengukur apa yang seharusnya di ukur, hasil penelitian yang valid bila terdapat kesamaan antara data yang terkumpul dengan data yang sesungguhnya terjadi pada obyek yang diteliti (Sugiyono, 1999:109).

\section{Uji Reliabilitas}

Menurut Umar (2000:135), untuk mengukur realibilitas dilakukan dengan menggunakan koefisien Coronbach Alpha. Hasil penelitian/koesioner dikatakan reliabel, bila terdapat kesamaan data dalam waktu yang berbeda. Kalau dalam obyek kemarin berwarna merah, maka sekarang dan besok berwarna merah.

\section{Uji Normalitas}

Pengujian normalitas dilakukan untuk mengetahui normal tidaknya suatu distribusi data (Supardi, 2011:129). 


\section{Statistik Deskriptif.}

Statistik Deskriptif adalah metode - metode yang berkaitan dengan pengumpulan dan penyajian suatu gugus data sehingga memberikan informasi yang berguna. (Supardi, 2013:31).

\section{Regresi Linear Sederhana}

Regresi linear sederhana yaitu regresi linear dengan satu variabel dependen dan satu variabel indevenden (variabel prediktor bebas). (Supardi, 2013:229). Model persamaannya adalah sebagai berikut: $\breve{Y}=\mathrm{a}+\mathrm{bx}$

Keterangan:

$\breve{\Upsilon}=$ Variabel dependent/kriteria (yang diprediksi)

$\mathrm{a}=$ Konstanta (bila harga Y untuk X $=0$ )

$\mathrm{b}=$ Angka arah atau koefisien regresi $\mathrm{x}=$ Nilai variabel (disiplin kerja)

\section{Uji Hipotesis}

Hipotesis merupakan jawaban sementara terhadap rumusan masalah penelitian, oleh karena itu rumusan masalah penelitian biasanya disusun dalam bentuk kalimat pertanyaan. (Sugiyono, 1999:51).

\section{Pengujian Secara Persial (Uji Statistik t)}

Uji $t$ untuk mengetahui variabel bebas yang diukur mempunyai pengaruh terhadap variabel terikatnya, apakah variabel independen (disiplin kerja dalam perspektif Islam) berpengaruh secara signifikan terhadap variabel dependen (produktivitas kerja) maka di gunakan $t$ hitung dengan rumus sebagai berikut:

$$
t=\frac{n - 2 \longdiv { }}{1-r^{2}}
$$

Keterangan:

$\mathrm{t}=$ thitung yang selanjutnya dikonsultasikan dengan ttabel

$r=$ Korelasi parsial yang ditemukan

$\mathrm{n}=$ Jumlah sampel

\section{Hasil Penelitian Dan Pembahasan \\ Variabel Y (Produktivitas)}

Dari hasil tanggapan responden terhadap produktivitas kerja dapat dilakukan dengan menggunakan skala likert sebagai berikut:

a. Jumlah skor ideal tertinggi adalah $5 \times 30=150$

b. Jumlah skor ideal terendah adalah $1 \times 30=30$

Skala nilai $=150-30=120$

Jumlah Interval $=5$ 
Dengan perhitungan interval sebagai berikut: Skala nilai: Kelas $=120: 5$ $=24$

Maka penilaian responden dikelompokan pada tabel berikut:

Tabel 1

Tabel Interval Variabel Y (Produktivitas Kerja)

Sumber: Sugiono (2011:184)

\begin{tabular}{|l|c|}
\hline $\begin{array}{l}\text { Interval } \\
\text { Koefisien }\end{array}$ & $\begin{array}{c}\text { Tingkat } \\
\text { Hubungan }\end{array}$ \\
\hline $0-30$ & Sangat Lemah \\
\hline $31-55$ & Lemah \\
\hline $56-80$ & Cukun Kuat \\
\hline $81-105$ & Kuat \\
\hline $106-130$ & Sangat Kuat \\
\hline
\end{tabular}

$\sum$ skor kriterium $=\sum$ skor tertinggi $\mathrm{x} \sum$ item $\mathrm{x} \sum$

responden

$=5 \times 20 \times 30$

$=3000$

$\sum$ skor pengumpulan data $=2387$ Lampiran 3

Kategori Ranking $=\sum$ Pengumpulan data: $\sum$

kriterium x $100 \%$

$=2387: 3000 \times 100 \%$

$=79 \%$

$0 \% 25 \% 50 \% 75 \% 100 \%$

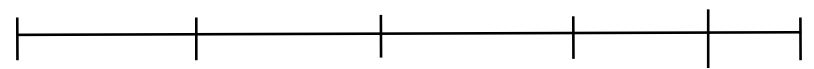

Gambar 1

Kurva Ranking Scale

Sumber: Sugiono (2011:99) 79\%

Berdasarkan data yang di peroleh dari 30 responden maka kurva diatas dapat disimpulkan bahwa produktivitas kerja sebesar 79\% dan dikategorikan cukup kuat.

\section{Variabel X (Disiplin Kerja Dalam Perspektif Islam)}

Dari hasil tanggapan responden terhadap disiplin kerja dapat dilakukan dengan menggunakan skala likert sebagai berikut:

c. Jumlah skor ideal tertinggi adalah $5 \times 30=150 \mathrm{~d}$. Jumlah skor ideal

terendah adalah $1 \times 30=30$

Skala nilai $=150-30=120$

Jumlah Interval $=5$

Dengan perhitungan interval sebagai berikut: Skala nilai: Kelas $=120: 5$ $=24$ 
Maka penilaian responden dikelompokan pada tabel berikut:

Tabel 2

Tabel Interval Variabel X (Disiplin Kerja Dalam Perspektif Islam)

\begin{tabular}{|l|l|}
\hline $\begin{array}{l}\text { Interval } \\
\text { Koefisien }\end{array}$ & \multicolumn{1}{|c|}{$\begin{array}{c}\text { Tingkat } \\
\text { Hubungan }\end{array}$} \\
\hline $0-30$ & Sangat Lemah \\
\hline $31-55$ & Lemah \\
\hline $56-80$ & Cukup Kuat \\
\hline $81-105$ & \multicolumn{1}{|c|}{ Kuat } \\
\hline $106-130$ & Sangat Kuat \\
\hline
\end{tabular}

Sumber: Sugiono (2011:189)

Dari hasil tanggapan responden terhadap disiplin kerja dapat

dikatagorikan sebagai berikut:

$\sum$ skor kriterium $=\sum$ skor tertinggi $\mathrm{x} \sum$ item $\mathrm{x} \sum$

responden

$=5 \times 20 \times 30$

$=3000$

$\sum$ skor pengumpulan data $=2333$ Lampiran 3

Kategori Ranting $=\sum$ Pengumpulan data: $\sum$ kriterium

$\mathrm{x} 100 \%$

$=2333: 3000 \times 100 \%$

$=77 \%$

0\% 25\% 50\% 75\% $77 \%$ 100\%

\section{Gambar 2 \\ Kurva Ranking Scale \\ Sumber: Sugiono (2011:99)}

Berdasarkan data yang di peroleh dari 30 responden maka kurva diatas dapat disimpulkan bahwa disiplin kerja sebesar 77\% dan dikategorikan cukup kuat.

\section{Analisis Deskripfif}

\section{Table 3}

\section{Analisis Statistik Deskriptif} Descriptive Statistics

\begin{tabular}{|l|lll}
\hline & Mean & $\begin{array}{l}\text { Std. } \\
\text { Deviation }\end{array}$ & N \\
Produktivitas & 61.27 & 4.690 & 30 \\
Disipln & 66.77 & 4.695 & 30
\end{tabular}

Sumber: data premier yang di olah dengan SPSS 21 
Pada tabel di atas menunjukan hasil olah data statistik deskriptif menunjukan bahwa dilihat dari 30 responden penelitian maka nilai ratarata variabel produktivitas adalah 61,27 dengan standar deviasi 4,690. Sedangkan untuk variabel disiplin menunjukan nilai rata-rata 66,77 dengan standar deviasi 4,695.

\section{Teknik Analisa Data}

\section{Uji Validitas}

Setelah penulis menyebarkan kuesioner kepada 30 karyawan, maka pada tabel selanjutnya menunjukan bahwa hasil olah data menggunkan rumus koefisien korelasi Product Moment Pearson. Apabila nilai koefisien korelasi butir item pertanyaan yang sedang diuji atau rhitung lebih besar dari nilai rtabel, maka dapat disimpulkan bahwa item pertanyaan tersebut merupakan konstruksi (construct) yang valid.

Tabel 5

Hasil Uji Validitas Variabel Y (Produktivitas Kerja)

\begin{tabular}{|l|l|l|l|}
\hline No. Pertanvaan & Rhituno \\
1 & 0.506 & Rtahel & Keterangan \\
\hline 2 & 0,361 & Valid \\
\hline 3 & 0,704 & 0,361 & Valid \\
\hline 4 & 0,673 & 0,361 & Valid \\
\hline 5 & 0,575 & 0,361 & Valid \\
\hline 6 & 0,602 & 0,361 & Valid \\
\hline 7 & 0,428 & 0,361 & Valid \\
\hline 8 & 0,412 & 0,361 & Valid \\
\hline 9 & 0,679 & 0,361 & Valid \\
\hline 10 & 0,607 & 0,361 & Valid \\
\hline 11 & 0,643 & 0,361 & Valid \\
\hline 12 & 0,408 & 0,361 & Valid \\
\hline 13 & 0,364 & 0,361 & Valid \\
\hline 14 & 0,679 & 0,361 & Valid \\
\hline 15 & 0,539 & 0,361 & Valid \\
\hline 17 & 0,643 & 0,361 & Valid \\
\hline 18 & 0,572 & 0,361 & Valid \\
\hline
\end{tabular}

Sumber: data premier yang diolah dengan SPSS 21 
Tabel 6

Hasil Uji Validitas Variabel X (Disiplin Kerja Dalam Perspektif Islam)

\begin{tabular}{|c|c|c|}
\hline No. Pertanvaan & Rhitung & Rtahel Keterangan \\
\hline 1 & 0.392 & 0,361 Valid \\
\hline 2 & 0.391 & 0.361 Valid \\
\hline 3 & 0.506 & 0.361 Valid \\
\hline 4 & 0.795 & 0,361 Valid \\
\hline 5 & 0.730 & 0,361 Valid \\
\hline 6 & 0.672 & 0,361 Valid \\
\hline 7 & 0.534 & 0.361 Valid \\
\hline 8 & 0.385 & 0,361 Valid \\
\hline 9 & 0.473 & 0,361 Valid \\
\hline 10 & 0.489 & 0.361 Valid \\
\hline 11 & 0.477 & 0,361 Valid \\
\hline 12 & 0,385 & 0,361 Valid \\
\hline 13 & 0.460 & 0.361 Valid \\
\hline 14 & 0.419 & 0,361 Valid \\
\hline 15 & 0.452 & 0,361 Valid \\
\hline 16 & 0.439 & 0.361 Valid \\
\hline
\end{tabular}

Sumber: data premier yang di olah dengan SPSS 21

\section{Uji Reliabilitas}

Uji reliabilitas digunakan untuk mengetetahui apakah butir-butir pertanyaan konsisten atau tidak. Suatu variabel dikatakan reliabel apabila memiliki Cronbach Alpha lebih besar dari 0,60 (Ghozali, 2005:41-45). Adapun perhitungannya sebagaimana tergambarkan dalam tabel sebagai berikut:

a. Variabel Produktivitas Kerja

\section{Tabel 7}

\section{Reliability Statistics}

\begin{tabular}{|c|c|} 
Cronbach's & N of Items \\
.828 & 17
\end{tabular}

Sumber: data premier yang di olah dengan SPSS 21

b. Variabel Disiplin Kerja Dalam Perpektif Islam

\section{Tabel 8}

\section{Reliability Statistics}

\begin{tabular}{|c|c|} 
Cronbach's & N of Items \\
.790 & 16
\end{tabular} \mid

Sumber: data premier yang di olah dengan SPSS 21

Dari hasil pengujian didapatkan perhitungan koefisien Cronbach Alpha dari variabel produkivitas kerja pada tabel 4.50 yaitu 0,828 lebih besar dari 0,60 . Variabel disiplin kerja dalam perspektif Islam pada tabel 4.53 
yaitu 0,790 lebih besar dari 0,60. Dengan demikian semua variabel dinyatakan baik dan reliabel.

\section{Uji Normalitas}

Tujuan uji normalitas adalah ingin mengetahui apakah distribusi sebuah data mengikuti atau mendekati distribusi normal, data yang baik adalah data yang mempunyai pola seperti distribusi normal, yakni distribusi data tersebut tidak menceng ke kiri atau menceng ke kanan (Singgih, 2010:43). Adapun kriteria pengujian normalitas adalah sebagai berikut:

- Jika angka signifikasi Uji Kolmogorov-Smirnov

Sig. $\geq 0,05$ maka data berdistribusi normal

- Jika angka signifikasi Uji Kolmogorov-Smirnov Sig. < 0,05 maka data berdistribusi tidak normal Uji normalitas dalam penelitian ini menggunakan uji kolmogorov-smirnov, sebagai berikut:

a. Variabel Produktivitas Kerja

\section{Tabel 9}

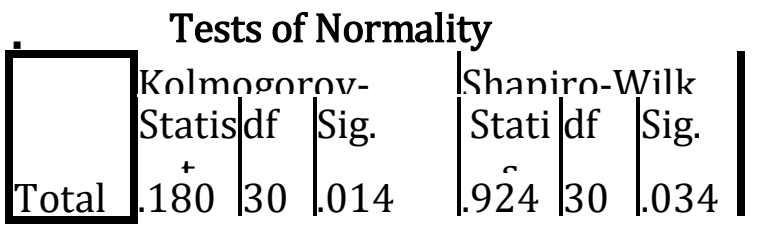

a. Lilliefors Significance Correction

Sumber: data premier yang di olah dengan SPSS 21

Berdasarkan pada Gambar 4.55 dapat dilihat bahwa nilai Sig. adalah sebesar 0,014. Menurut kriteria, apabila angka signifikasi Uji KolmogorovSmirnov Sig. $\geq 0,05$ maka data berdistribusi normal. Karena nilai Sig. adalah sebesar $0,014>0.05$. maka data yang digunakan dalam penelitian ini berdistribusi normal.

b. Variabel Disiplin Kerja Dalam Perpektif Islam

Tabel 10

Tests of Normality

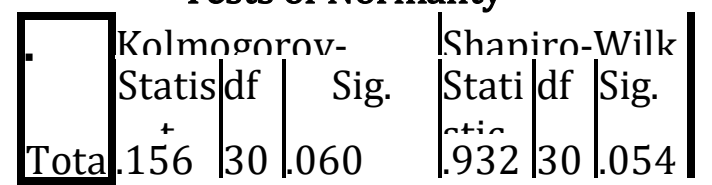

a. Lilliefors Significance Correction

Sumber: data premier yang di olah dengan SPSS 21

Berdasarkan pada tabel 4.56, dapat dilihat bahwa nilai Sig. adalah sebesar 0,060. Menurut kriteria, apabila angka signifikasi Uji Kolmogorov- 
Smirnov Sig. $\geq 0,05$ maka data berdistribusi normal. Karena nilai Sig. adalah sebesar $0,060>0.05$. maka data yang digunakan dalam penelitian ini berdistribusi normal.

\section{Analisis Regresi Sederhana}

Regresi linear sederhana yaitu regresi linear dengan satu variabel dependen dan satu variabel indevenden (Supardi, 2013:229).

Tabel 11

\begin{tabular}{|c|c|c|c|c|c|}
\hline & \multicolumn{5}{|c|}{ Uji Regresi Sederhana } \\
\hline Model & Unsta & dardized & Standardized & $\mathrm{t}$ & Sig. \\
\hline & B & Std. Error & Beta & & \\
\hline (Constant) & 5.830 & 7.022 & & .830 & .413 \\
\hline 1 & .830 & .105 & .831 & 7.913 & .000 \\
\hline
\end{tabular}

a. Dependent Variable: Produktivitas

Sumber: data premier yang di olah dengan SPSS 21

Berdasarkan hasil tabel 11 selanjutnya menggambarkan persamaan regresi sebagai berikut:

$\breve{Y}=\mathrm{a}+\mathrm{bx}$

$\breve{\Upsilon}=5,830+0,830 \mathrm{x}$

Nilai konstanta sebesar 5,830 menyatakan bahwa jika nilai dari variabel independen nol maka besarnya Y produktivitas kerja adalah sebesar 5,830 .

Koefisien regresi X disiplin kerja dalam perspektif Islam sebesar 0,830 menyatakan bahwa setiap penambahan satu variabel dari X disiplin kerja dalam perspektif Islam maka nilai Y produktivitas kerja akan bertambah 0,830 dimana variabel lain dianggap konstan.

\section{Analisis Koefisien Determinasi}

Tabel 12

Determinasi Regresi

\begin{tabular}{|c|c|l|l|c|}
\hline Model & $\begin{array}{l}\mathrm{R} \\
\text { Square }\end{array}$ & $\begin{array}{c}\text { Adjusted } \\
\mathrm{R}\end{array}$ & $\begin{array}{c}\text { Std. } \\
\text { Error } \\
691\end{array}$ \\
\hline 1 & .680 & 2.653 \\
\hline
\end{tabular}

Sumber: data premier yang di olah dengan SPSS 21

Berdasarkan hasil tabel 4.58 koefisien determinasi $\left(r^{2}\right)$ sebesar 0,831 .

Maka dapat dihitung dengan rumus: $\mathrm{Kd}=\mathrm{r}^{2} \times 100 \%$ 
Dari perhitungan tersebut, diperoleh nilai R Square sebesar $69 \%$ yang artinya disiplin kerja dalam perspektif Islam mempengaruhi produktivitas kerja karyawan sebesar 69\%. Dan sisanya (100\%-69\% $=31 \%$ ) dipengaruhi oleh faktor lain.

\section{Pengujian Hipotesis dan Pembahasan}

Berdasarkan hasil tabel 11 menunjukan bahwa nilai thitung untuk disiplin kerja dalam perspektif Islam adalah 7,913 sedangkan ttabel bisa didapat pada tabel t-test, dengan a $=0,05$. $\mathrm{Df}=30$ (nilai $\mathrm{n}-2$, di mana $\mathrm{n}$ adalah jumlah data, 30-2 =28). Didapat di ttabel adalah 1,701. Karena thitung lebih besar dari tabel $(7,913>1,701)$ maka $\mathrm{H}_{\mathrm{O}}$ ditolak dan $\mathrm{Ha}$ diterima, yang berarti adanya pengaruh antara disiplin kerja dalam perspektif Islam terhadap produktivitas kerja.

Dapat dilihat bahwa nilai probabilitas pada kolom signifikan adalah 0,000 lebih kecil dari 0,05 $(0,000<0,05)$. Dengan demikian $\mathrm{H}_{\mathrm{O}}$ ditolak dan Ha diterima atau koefisien regresi signifikan, sehingga mempunyai kesimpulan yaitu disiplin kerja dalam perspektif Islam berpengaruh positif dan signifikan terhadap produktivitas kerja karyawan.

\section{Pembahasan Penelitian}

Bekerja dalam suatu organisasi hendaklah selalu taat terhadap aturan yang telah ditetapkan oleh pimpinan maupun instasi atau organisasi sesuai dengan ajaran Islam. Hal ini dijelaskan dalam Al-Quran surat AnNisa ayat 59 yang berbunyi "Wahai orang-orang yang beriman, taatlah kamu kepada Allah dan taatlah kepada rasul-Nya dan kepada Ullil Amri dari (kalangan) kamu". Bekerja dapat dikatakan disiplin apabila karyawan dapat datang tepat waktu dan menyelesaikan pekerjaan sesuai dengan waktu yang telah ditetapkan oleh perusahaan. Melaksanakan pekerjaan dengan niat ibadah, karyawan sudah bisa melaksanakan sholat tepat pada waktunya. Hal tersebut akan mempengaruhi prilaku karyawan dan akan mengaplikasikannya dalam prilaku bekerja sehari-hari seperti disiplin dalam bekerja dan bertanggung jawab atas pekerjaannya.

Berdasarkan hasil penelitian yang dilakukan terhadap 30 responden pada variabel Y (produktivitas kerja) yang terdiri dari kuntitas kerja, kualitas kerja dan ketepatan waktu. Dari hasil jawaban memiliki nilai rata-rata sebesar 79\%Bmaka masuk dalam kategori cukup kuat. Pada variabel X (disiplin kerja dalam perspektif Islam) yang terdiri dari masuk kerja tepat waktu, penggunaan waktu secara efekif, tidak pernah mangkir/tidak kerja, mematuhi semua peraturan organisai atau perusahaan, target pekerjaan dan membuat laporan kerja harian. Dari 
hasil jawaban memiliki nilai rata-rata sebesar 77\% maka masuk dalam kategori cukup kuat.

Koefisien determinasi sebesar 69\% dan sisanya dipengaruhi oleh faktor lain yang tidak diteliti oleh penulis. Adapun koefisien regresi $b$ sebesar 0,830 yang bertanda positif itu menunjukan adanya pengaruh positif disiplin kerja dalam perspektif Islam terhadap produktivitas kerja karyawan.

Nilai thitung adalah 7,913 karena thitung lebih besar dari ttabel $(7,913>1,701)$, dari probabilitas pada kolom signifikan adalah 0,000 lebih kecil dari 0,05 $(0,000<0.05)$. Dengan demikian $\mathrm{H}_{\mathrm{O}}$ ditolak dan $\mathrm{Ha}$ diterima atau koefisien regresi signifikan, sehingga mempunyai kesimpulan yaitu disiplin kerja dalam perspektif Islam berpengaruh positif secara signifikan terhadap produktivitas kerja karyawan. Ini berarti bahwa disiplin kerja juga penting dalam meningkatkan produktivitas kerja karyawan.

\section{Kesimpulan}

Dengan melihat hasil penelitian yang telah dibahas, maka dapat disimpulan sebagai berikut:

Dari hasil pengujian yang dilakukan terbukti bahwa disiplin kerja dalam perspektif Islam berpengaruh terhadap produktivitas kerja karyawan. Berdasarkan penelitian ini produktivitas kerja akan meningkat apabila disiplin kerja dapat ditingkatkan. Hal ini ditunjukan dari Nilai thitung adalah 7,913 karena thitung lebih besar dari ttabel $(7,913>$ 1,701), dari probabilitas pada kolom signifikan adalah 0,000 lebih kecil dari $0,05(0,000<0.05)$. Dengan demikian $\mathrm{H}_{\mathrm{O}}$ ditolak dan Ha diterima atau koefisien regresi signifikan, sehingga mempunyai kesimpulan yaitu disiplin kerja dalam perspektif Islam berpengaruh positif secara signifikan terhadap produktivitas kerja karyawan. Ini berarti bahwa disiplin kerja juga penting dalam meningkatkan produktivitas kerja karyawan.

\section{Daftar Pustaka}

Al-Qur'an dan Terjemahan. Mushaf Al-Qur'an, Jakarta: Pustaka Agung Harapan, 2006.

Afandi, Pandi, Concept \& Indicator Human Resources Management For Managemen Researth, Yogyakarta: Deepublish, 2016.

Artyasa, S. Usin, Ingin Hidup Sukses dan Berkah Awali Dengan Bismilah, Jakarta: Ruang Kata Imprint Kawasan Pustaka, 2012.

Afriyani, Fitri Cristian. 2016. Pengaruh Disiplin Kerja Terhadap Produktivitas Kerja Karyawan Bagian Produksi Pabrik Kelapa 
Sawit PT. Perkebunan Nusantara, Jurnal Universitas Riau. Vol. 3 No. 1 (Februari 2016).

Hasan, Umar, Metode Penelitian, Jakarta: Rajagrafindo Persada, 2000. Mulianto, Sindu, Eko Ruddy Cahayadi, dkk, Supervisi Diperkaya Prespektif Syariah, Jakarta: Gramedia, 2006.

Mursi, Abdul Hamid, SDM Yang Produktif Pendekatan Al- Quran dan Sains, Jakarta: Gema Insani Presss, 1997.

Santoso, Singgih, Statistik Multivariat, Jakarta: Gramedia, 2010.

Sugiyono, Metode Penelitian Bisnis, Bandung: Alfabeta, 1999.

Sugiyono, Metode Penelitian Kuantitatif Kualitatif dan R\&D, Bandung: Alfabeta, 2011.

Suparadi, Aplikasi Statistika Dalam Penelitian, Jakarta: Cange Publication, 2013.

Sutrisno, Edy, Manajmen Sumber Daya Manusia, Jakarta: Kencana Prenada Media Grup, 2014.

Tasmara, K.H. Toto, Membudayakan Etos Kerja Islamai, Jakarta: Gema Insani, 2002.

Umar, Husein, Sumber Daya Manusia Dalam Organisasi, Jakarta: Gramedia, 2005. 